\title{
An Alkaliphilic and Xylanolytic Paenibacillus Species Isolated from the Gut of a Soil-Feeding Termite
}

\author{
Moriya OHKUMA ${ }^{1,2,3 *}$, HaJime SHIMIZU ${ }^{1,4}$, TAKSAWAN THONGARAM ${ }^{1,5}$, SAORI KOSONO ${ }^{1,3}$, KAZUHITO MORIYA $^{4}$, \\ SAVITR TRAKULNALEAMSAI ${ }^{5,6}$, NAPAVARN NOPARATNARAPORN ${ }^{5,6}$ and TOSHIAKI KUDO ${ }^{1,3,7}$ \\ ${ }^{1}$ RIKEN, Wako, Saitama 351-0198, Japan \\ ${ }^{2}$ PRESTO, Japan Science and Technology Agency (JST), Wako, Saitama 351-0198, Japan \\ ${ }^{3}$ ICORP, JST, Wako, Saitama 351-0198, Japan \\ ${ }^{4}$ Hokkaido Sugar Co., Ltd., Kitagami 101-1, Kitami, Hokkaido 099-1583, Japan \\ ${ }^{5}$ Bioscience Program, Graduate School, Kasetsart University, Bangkok 10900, Thailand \\ ${ }^{6}$ Department of Microbiology, Kasetsart University, and Kasetsart University Research and Development \\ Institute (KURDI), Bangkok 10900, Thailand \\ ${ }^{7}$ Graduate School of Integrated Science, Yokohama City University, Tsurumi, Yokohama 230-0045, Japan
}

(Received June 22, 2003-Accepted July 11, 2003)

Gut portions of soil-feeding termites belonging to the subfamily Termitinae generally show extensive alkalinity. An alkaliphilic and xylanolytic bacterium, strain SM-XY60, was isolated from the gut of such a soil-feeding termite Sinocapritermes mushae. This bacterium was a strictly aerobic endospore-forming rod, capable of growth at $\mathrm{pH} 6.5$ to 10.5 , and showing optimal growth at $\mathrm{pH}$ 9. The strain grew well on an alkaline medium containing $\mathrm{K}_{2} \mathrm{CO}_{3}$, but not $\mathrm{Na}_{2} \mathrm{CO}_{3}$. $16 \mathrm{~S}$ rDNA analysis and physiological characterization revealed this strain to be a member of the genus Paenibacillus but distinct from any known species. The xylanase produced by the alkaline growing cells showed substantial activity and stability at high $\mathrm{pH}$, implying an adaptation of the enzyme to the gut alkaline environment. The isolation of this alkaliphile suggests that the insect gut is of ecological significance for alkaliphiles.

Key words: alkaliphile, Paenibacillus, symbiosis, termite, xylanase

Termites (order Isoptera) harbor a diverse variety of microorganisms in their gut. The relationship between termites and the microorganisms in their gut is one of the most fascinating examples of symbiosis, and this relationship contributes to the digestion of ligno-cellulosic matter ${ }^{29}$. Termites are ordinarily divided into two groups, so-called lower and higher termites. Lower termites harbor symbiotic cellulolytic protists in the gut while higher termites (family Termitidae) do not. Lower termites usually feed on wood, but higher termites show considerable variation in their feeding behavior. Soil-feeding termites feed exclusively on soil, presumably deriving nutrition from the humic compounds therein ${ }^{2,3,28)}$. However, analysis of gut contents

\footnotetext{
* Corresponding author; E-mail: mohkuma@postman.riken.go.jp, Tel: +81-48-467-9648, Fax: +81-48-462-4672
}

shows that soil-feeding termites feed on heterogeneous matter containing plant tissues and microbial cells besides a large proportion of minerals and humus particles ${ }^{37}$. Although soil-feeding termites play an ecologically important role due to their great abundance especially in tropical areas, our knowledge about the specific nutritive components utilized and their metabolism within the gut is limited ${ }^{2,7}$. Nevertheless, it is considered that the gut microflora are responsible for the degradation of soil organic matter.

Interestingly, the hindgut portions of soil-feeding members of the subfamily Termitinae show extreme alkalinity (up to $>\mathrm{pH} 12$ ), representing one of the most extreme alkaline environments ever found within biological systems ${ }^{4,5,9)}$. It is reported that gut alkalinity is effective in the solubilization of humic materials in the ingested soil ${ }^{22}$, but aromatic components of humic materials are not substantially 
utilized $^{21)}$. Rather, polysaccharides and bacterial components are sufficiently transformed and mineralized ${ }^{20,21)}$.

A great number of alkaliphilic strains from various environments and their alkaline enzymes have been shown to be useful for a wide variety of industrial processes ${ }^{19}$. Due to the nature of soil-feeding termites described above, their gut is expected to be an attractive source of alkaliphilic microorganisms capable of degrading ligno-cellulosic substances. Despite the isolation of a large number of bacteria including ligno-cellulose degraders from the gut of various termite species $^{26)}$, there has been no report, to our knowledge, of the isolation and description of alkaliphilic bacteria from the gut of termites. Here, we report the physiological characterization of an alkaliphilic and xylanolytic Paenibacillus strain isolated from the gut of a soil-feeding termite, and also describe some properties of the xylanolytic enzyme produced by this strain. Along with an accompanying report $^{39)}$, the isolation of alkaliphiles suggests that the insect gut is of significance to the ecology of alkaliphiles.

\section{Materials and Methods}

\section{Isolation and cultivation}

A soil-feeding termite Sinocapritermes mushae (Termitidae, Termitinae) was collected in Okinawa prefecture, Japan. After the exterior surfaces of the termite had been extensively washed with distilled water, the guts were withdrawn using forceps. The guts were homogenized in distilled water and spread onto xylan-containing alkaline solid medium (polypeptone [Difco] $10 \mathrm{~g}$, yeast extract [Difco] $5 \mathrm{~g}, \mathrm{NaH}_{2} \mathrm{PO}_{4} 1 \mathrm{~g}, \mathrm{MgSO}_{4}-7 \mathrm{H}_{2} \mathrm{O} 0.2 \mathrm{~g}, \mathrm{~K}_{2} \mathrm{CO}_{3} 10 \mathrm{~g}$, oat spelts xylan [Sigma] $5 \mathrm{~g}$, and agar $15 \mathrm{~g}$ dissolved in $1 \mathrm{~L}$ of distilled water). After incubation for two days at $30^{\circ} \mathrm{C}$, a xylan-degrading bacterium (designated as strain SM-XY60) was isolated and characterized further. The isolate was cultured at neutral $\mathrm{pH}$ with medium containing $\mathrm{KCl}$ instead of $\mathrm{K}_{2} \mathrm{CO}_{3}$. The strain has been deposited into the Japan Collection of Microorganisms as JCM10914.

\section{Physiological and chemotaxonomic characteristics}

The characterization of phenotypic features was carried out as described previously ${ }^{15,33)}$. Tests examining the utilization of various substrates as the sole carbon source were performed using GP Biolog microplates according to the manufacturer's instructions. The diamino acid in the peptidoglycan and menaquinones were analyzed as described previously ${ }^{25}$. The $\mathrm{G}+\mathrm{C}$ content of the DNA was determined by a previously reported method ${ }^{38)}$.

\section{S rDNA analysis}

The 16S rRNA gene was amplified using as primers 5'-ATTGGATCCGTTTGAGCMTGGCTCAG-3' [27F] and 5'-TGAGTCGACACGGGCGGTGTGTRC-3' [1392R]. Amplified 16S rDNA purified with a Wizard PCR prep DNA purification kit (Promega) was used as a sequencing template. In addition to the sequencing primers previously described ${ }^{31,32)}$, the following primers were used: 5'-ACTCCTACGGGAGGCAGC-3' (350F), 5'-TGCTGCCTCCCGTAGGAG-3' (350R), and 5'-TTACCGCRGCTGCTGGCA3' (520R). DNA sequencing was performed with the ABI PRISM BigDye Terminator Cycle Sequencing Ready Reaction kit (Perkin Elmer) and with an automatic sequence analyzer (ABI model 377). The nucleotide sequence data determined in this study will appear in the EMBL, GenBank, and DDBJ databases under accession number AB046581. The sequence determined in this study was compared with $16 \mathrm{~S}$ rDNA sequences in the databases. Sequences were aligned using the CLUSTAL W package ${ }^{40)}$, then checked manually. Construction of a neighbor-joining tree ${ }^{34)}$ and bootstrap analysis for evaluation of the tree's topology ${ }^{13)}$ were carried with the PHYLIP package version $3.5 \mathrm{c}^{12}$.

\section{Enzyme assay}

The culture supernatant was concentrated with Centricon10 (Amicon) before use in the enzyme assay. Enzyme activity was assayed in $10 \mathrm{mM}$ phosphate buffer $(\mathrm{pH} \mathrm{7.0)}$ at $50^{\circ} \mathrm{C}$ using $0.5 \%$ oat spelts xylan (Sigma) as the substrate. It was suspended homogeneously by ultrasonic treatment prior to its addition to the reaction mixture. The amount of reducing sugar liberated was determined using 3,5-dinitrosalicylic acid. One unit of enzyme activity was defined as the amount of enzyme that released $1 \mu \mathrm{mol}$ of reducing sugar as the xylose equivalent. The protein concentration was determined using a Bio-Rad DC Protein Assay kit with bovine serum albumin as the standard.

\section{Results}

An alkaliphilic and xylanolytic strain SM-XY60 was isolated from the gut of the soil-feeding termite Sinocapritermes mushae. The bacterium was found to be a strictly aerobic and slightly curved rod forming an ellipsoidal spore in swollen sporangia. The characteristics of strain SM-XY60 are summarized in Table 1. The $\mathrm{pH}$ range for growth was 6.5 to 10.5 and optimum growth occurred at $\mathrm{pH} 9$, indicating that the strain was alkaliphilic. The temperature range for growth was $15^{\circ} \mathrm{C}$ to $40^{\circ} \mathrm{C}$. Growth was inhibited in the 
Table 1. Characteristics of strain SM-XY60 in comparison to allied Paenibacillus species.

\begin{tabular}{|c|c|c|c|c|}
\hline Characteristics & SM-XY60 & P. lautus ${ }^{\mathrm{a}}$ & P. glucanolyticus ${ }^{\mathrm{b}}$ & P. campinasensis $^{\mathrm{c}}$ \\
\hline Anaerobic growth & - & + & + & + \\
\hline Growth at $5 \% \mathrm{NaCl}$ & - & + & + & + \\
\hline Growth at pH 5.7 & - & + & + & - \\
\hline \multicolumn{5}{|l|}{ Optimum growth: } \\
\hline $\mathrm{pH}$ & 9 & 7 & 7 & 10 \\
\hline Temperature $\left({ }^{\circ} \mathrm{C}\right)$ & 37 & $28-30$ & 30 & 40 \\
\hline Catalase & + & + & + & + \\
\hline Oxidase & + & - & + & - \\
\hline Nitrate reduction & - & + & + & ND \\
\hline \multicolumn{5}{|l|}{ Hydrolysis of: } \\
\hline Casein & + & - & + & + \\
\hline Starch & + & + & + & + \\
\hline Gelatin & + & + & + & + \\
\hline Urea & - & + & - & - \\
\hline \multicolumn{5}{|l|}{ Degradation of: } \\
\hline $\mathrm{CMC}^{\mathrm{d}}$ & + & + & + & ND \\
\hline Xylan & + & ND & - & ND \\
\hline \multicolumn{5}{|l|}{ Acid production from: } \\
\hline D-Glucose & + & + & + & + \\
\hline D-Xylose & + & + & + & + \\
\hline Raffinose & + & - & + & - \\
\hline Sorbitol & - & + & + & + \\
\hline Cell wall peptidoglycan ${ }^{\mathrm{e}}$ & meso-DAP & meso-DAP & meso-DAP & meso-DAP \\
\hline Menaquinone & MK-7 & MK-7 & MK-7 & MK-7 \\
\hline $\mathrm{G}+\mathrm{C}$ content & 49.2 & $50-52$ & 48 & 50.9 \\
\hline $16 \mathrm{~S}$ rDNA sequence identity to SM-XY60 & & $96.0-96.6 \%$ & $95.7-96.1 \%$ & $94.8 \%$ \\
\hline
\end{tabular}

- , negative reaction; +, positive reaction; $\mathrm{ND}$, not determined.

${ }^{a}$ Data from Heyndrickx et al. ${ }^{16)}$ and Nakamura ${ }^{27)}$.

${ }^{\mathrm{b}}$ Data from Alexander and Priest ${ }^{1)}$ and Shida ${ }^{36}$.

${ }^{\mathrm{c}}$ Data from Yoon et al. ${ }^{41)}$ Acid production from four substrates is incorporated from the data using a Biolog microplate.

${ }^{\mathrm{d}} \mathrm{CMC}$, carboxy methyl cellulose.

e meso-DAP, meso-diaminopimelic acid.

presence of $5 \% \mathrm{NaCl}$. Strain SM-XY60 grew well in the medium containing $1 \% \mathrm{~K}_{2} \mathrm{CO}_{3}$, but, when $\mathrm{K}_{2} \mathrm{CO}_{3}$ was replaced with $1 \% \mathrm{Na}_{2} \mathrm{CO}_{3}$, growth of the strain did not occur.

Phylogenetic analysis of the partial nucleotide sequence of the $16 \mathrm{~S}$ rDNA (1375 bp) revealed that strain SM-XY60 belonged to the genus Paenibacillus (Fig. 1). However, it was found to represent a lineage distinct from previously known Paenibacillus species in the phylogenetic tree. Strain SM-XY60 showed close phylogenetic relationships with $P$. lautus, $P$. glucanolyticus, and P. campinasensis, and groupings with the former two species were supported by a high bootstrap value, $92.8 \%$. The strain demonstrated 96.6-96.0\% nucleotide sequence identity with $P$. lautus,
96.1-95.7\% with P. glucanolyticus, and $94.8 \%$ with $P$. campinasensis.

The $\mathrm{G}+\mathrm{C}$ content of the DNA of strain SM-XY60 was $49.2 \pm 0.5 \%$, which fell within the range for Paenibacillus species (45 to $54 \%$ ). Also, menaquinone 7 as the principal quinone and meso-diaminopimelic acid in the cell-wall peptidoglycan were characteristic of the genus Paenibacillus $^{16,36)}$.

Table 1 shows comparisons of some representative characters of strain SM-XY60 and the three related Paenibacillus species. The absence of anaerobic growth and the growth inhibition in the presence of $5 \% \mathrm{NaCl}$ were distinct features of strain SM-XY60. The alkaliphilic nature of 


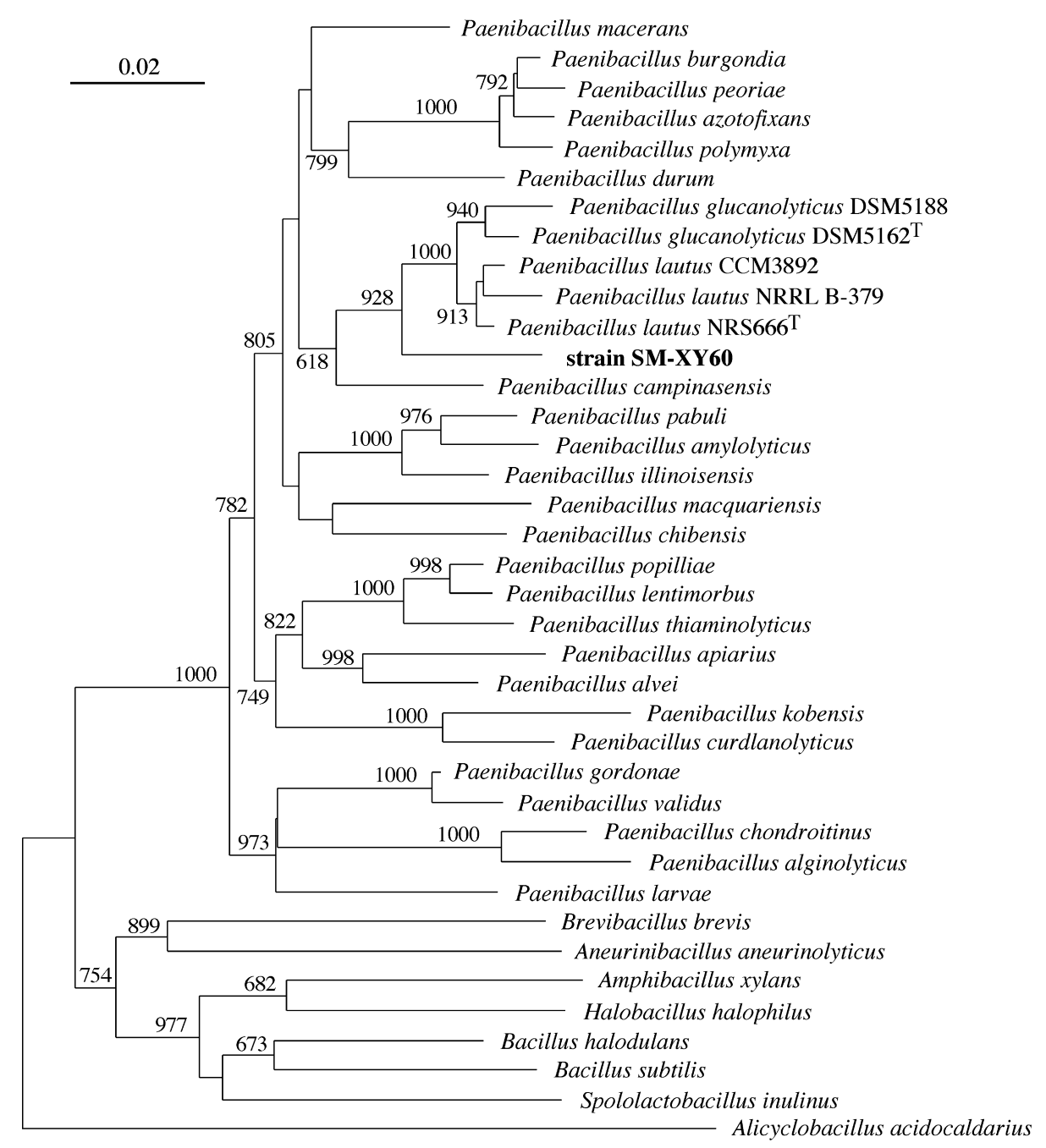

Fig. 1. Phylogenetic position of strain SM-XY60 in relation to Paenibacillus species based on the 16S rRNA gene sequence. Alicyclobacillus acidocaldarius was used as an outgroup for the phylogenetic analysis. Bootstrap values above 500 from 1,000 resamplings are shown for each node. The scale bar represents 0.02 substitutions per nucleotide position.

the growth was absent in the case of $P$. lautus $^{27)}$ and P. glucanolyticus $^{1}$. P. campinasensis was isolated as an alkaliphile $^{41)}$, but strain SM-XY60 and P. campinasensis differed in several physiological features. In the test examining the utilization of various substrates oxidized as sole carbon sources on Biolog microplates, utilization of 45 out of 95 substrates differed between them (data not shown). The results indicated that strain SM-XY60 probably represented a novel species of Paenibacillus, though the specific epithet for this was not given in this study.

Xylanase activity in the culture media was detected at levels as high as $0.54 \mathrm{U} / \mathrm{mg}$ protein when the cells were grown at $\mathrm{pH} 10$ (Fig. 2). The effect of $\mathrm{pH}$ on the activity and stability of the enzyme is shown in Fig. 3. The xylanase was stable over a broad range of $\mathrm{pH}$ and showed substantial activity, more than $80 \%$ of the level observed under optimum conditions, between $\mathrm{pH} 5$ and $\mathrm{pH}$ 9.5. Xylanase activity was hardly detected (less than $0.07 \mathrm{U} / \mathrm{mg}$ protein) when the cells were grown at neutral $\mathrm{pH}$ although the growth rate of the cells did not differ significantly from that at alkaline $\mathrm{pH}$. The enzyme was stable at $40^{\circ} \mathrm{C}$ for two hours and the optimal temperature for activity was $55^{\circ} \mathrm{C}$.

\section{Discussion}

A large number of lignocellulose decomposers that contained novel species have been isolated from the gut of termites including soil-feeders ${ }^{26,35,42}$. However, to our 


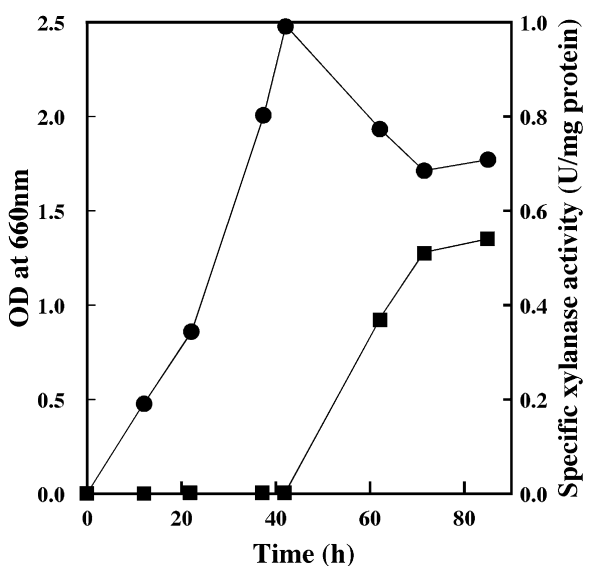

Fig. 2. Cell growth and xylanase production of strain SM-XY60. The cells were grown at $\mathrm{pH} 10.0$ (solid circles). Xylanase activity in the culture medium was measured (solid squares)

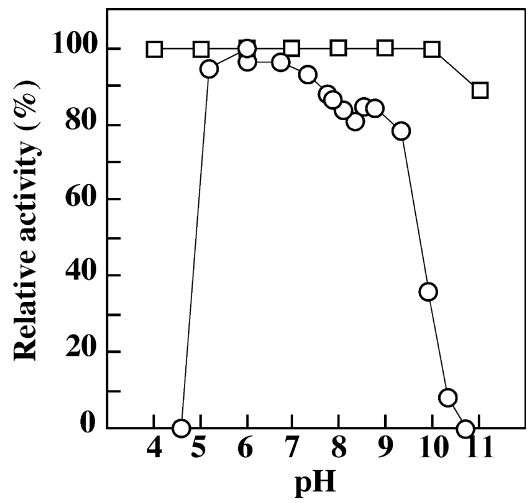

Fig. 3. Effect of $\mathrm{pH}$ on the xylanase activity. The enzyme activity was measured under various $\mathrm{pH}$ conditions at $50^{\circ} \mathrm{C}$. The optimal activity $(2.8 \mathrm{U} / \mathrm{ml})$ was obtained at $\mathrm{pH} 6.0$ and was taken as $100 \%$. The $\mathrm{pH}$ of the reaction mixtures was adjusted with acetate buffer ( $\mathrm{pH} 4.0-6.0$ ), phosphate buffer ( $\mathrm{pH}$ 6.0-8.0), Tris-HCl buffer ( $\mathrm{pH}$ 8.0-9.0) or glycine- $\mathrm{NaOH}$ buffer ( $\mathrm{pH} 8.5-11.0)$, and relative activity is shown (open circles). The $\mathrm{pH}$ stability of the enzyme was investigated by incubating the enzyme under various $\mathrm{pH}$ conditions at $30^{\circ} \mathrm{C}$ for two hours. The residual activity relative to that observed at $\mathrm{pH} 6.0(2.3 \mathrm{U} / \mathrm{ml})$, taken as $100 \%$, is shown (open squares).

knowledge, this is the first report of the isolation and characterization of an alkaliphile from the termite gut. Although Brune ${ }^{7)}$ mentioned the presence of a number of alkaliphiles in extremely alkaline gut regions, no taxonomic or physiological description of them was given. In the accompanying paper ${ }^{39)}$, the presence of Paenibacillus species related closely to strain SM-XY60 was revealed in the gut of some Termitinae termites in Thailand by culture-based and culture-independent analyses. The species represented by strain SM-XY60 is probably shared by some members of the subfamily Termitinae whose guts have extreme alkaline regions. On the other hand, in an extensive survey of the $16 \mathrm{~S}$ rDNA clones of the gut microbial community of a lower termite Reticulitermes speratus ${ }^{17,18,32)}$, we failed to detect a 16S rDNA sequence affiliated to Paenibacillus. There are two reports about the isolation of Paenibacillus from lower termites ${ }^{35,42)}$. One report is on a xylanolytic Paenibacillus macerans and the other, a cellulolytic Paenibacillus sp. but the two species are distantly related to strain SM-XY60. Strain SM-XY60 was distinct from any previously known Paenibacillus species with respect to both $16 \mathrm{~S}$ rDNA sequence similarity and several physiological features. Thus, this strain should represent a novel species of Paenibacillus. The gut community of termites consists of a large number of yet-unknown microorganisms ${ }^{29,30}$. Considering the immense diversity of termites particularly soil-feeders, their guts are likely to be valuable sources of lignocellulose-decomposing alkaliphiles which, along with their enzymes, may be useful in applied science.

Although the extent to which gut symbionts contribute to digestion remains unknown, the gut alkalinity may affect their physiological and biochemical properties. The xylanase produced when strain SM-XY60 was grown at alkaline $\mathrm{pH}$ showed not only stability over a broad range of $\mathrm{pH}$ but also significant activity at high $\mathrm{pH}$ (approximately $80 \%$ of the optimal level at $\mathrm{pH} 9.5$ ). The enzyme was produced in substantial amounts only under alkaline conditions. These enzymatic characters are beneficial for adaptation to alkaline environments in the termite gut. This strain also showed cellulolytic activity, though it was weak, under both alkaline and neutral conditions. Probably, the strain plays a role in the digestion of hemicellulose and cellulose in the ingested soil.

The ion content in the gut may also affect the physiology of the isolate. In some soil-feeding termites, portions of the gut corresponding to regions of high $\mathrm{pH}$ are known to contain large amounts of $\mathrm{K}^{+}$). In caterpillars, whose gut is also known to be an alkaline environment, elevation of the gut $\mathrm{pH}$ is evidently linked to potassium transport and the net accumulation of $\mathrm{K}_{2} \mathrm{CO}_{3}{ }^{11}$. The finding that strain SM-XY60 grew well in the alkaline medium containing $\mathrm{K}_{2} \mathrm{CO}_{3}$ but not $\mathrm{Na}_{2} \mathrm{CO}_{3}$ may be a reflection of the chemical conditions in the gut. Generally, alkaliphiles have been isolated in alkaline media containing $\mathrm{Na}_{2} \mathrm{CO}_{3}{ }^{19}$, although some are known to grow in alkaline media containing $\mathrm{K}_{2} \mathrm{CO}_{3}^{23,24)}$. The dependence of growth on $\mathrm{K}_{2} \mathrm{CO}_{3}$ instead of $\mathrm{Na}_{2} \mathrm{CO}_{3}$ may require special attention in studies involving the isolation of alkaliphiles from the gut of certain arthropods. In the 
accompanying paper ${ }^{39)}$, some of the alkaliphiles isolated from several termite species indeed preferred $\mathrm{K}^{+}$to $\mathrm{Na}^{+}$for their growth.

One may consider that the strict aerobic phenotype of strain SM-XY60 is a contradiction to its inhabitance within the gut. However, a study using a microelectrode has revealed that the gut environment is micro-oxic and that oxygen penetrates the gut through the gut periphery ${ }^{8}$. Such oxygen is consumed through the autoxidation of humic substances in the case of soil-feeding termites ${ }^{22}$ and probably through the rapid and continuous activities of gut symbionts in most termites ${ }^{8)}$. In fact, a large number of strict aerobic bacteria have been isolated from termite guts $^{26)}$.

Isolation of the alkaliphile suggests that the gut of certain termites is a niche for alkaliphiles. In addition to soil-feeding termites of the subfamily Termitinae, extensive alkalinity of the gut is a common feature of the termites of this subfamily, regardless of their feeding behavior ${ }^{5)}$. An elevation of gut $\mathrm{pH}$ to some extent is also evident in other subfamilies of higher termites except fungus-growing termites (subfamily Macrotermitinae). Moreover, high $\mathrm{pH}$ values within the gut have been reported for certain lepidopteran, coleopteran and dipteran larvae ${ }^{10,11,14)}$. Considering the abundance and diversity of arthropods as well as termites, the arthropod guts may be a rich reservoir of alkaliphiles.

\section{Acknowledgments}

This work was partially supported by grants for the Bioarchitect Research Program and the Eco Molecular Science Research Program from RIKEN. One of the authors (T.T.) is a recipient of the Asia Joint Graduate School Program of RIKEN. We thank M. Kitada for valuable comments.

\section{References}

1) Alexander, B. and F.G. Priest. 1989. Bacillus glucanolyticus, a new species that degrades a variety of $\beta$-glucans. Int. J. Syst. Bacteriol. 39: 112-115.

2) Brauman, A., D.E. Bignell and I. Tayasu. 2000. Soil-feeding termites: biology, microbial associations and digestive mechanisms. p. 233-259. In T. Abe, D.E. Bignell and M. Higashi (ed.), Termites: evolution, sociality, symbioses, Ecology. Kluwer Academic Publishers, Dordrecht, Netherlands.

3) Bignell, D.E. 1994. Soil-feeding and gut morphology in higher termites. p. 131-158. In J.H. Hunt and C.A. Nalepa (eds.), Nourishment and evolution in insect societies. Westview Press, Boulder.

4) Bignell, D.E. and J.M. Anderson. 1980. Determination of $\mathrm{pH}$ and oxygen status in the guts of lower and higher termites. J. Insect
Physiol. 26: 183-188.

5) Bignell, D.E. and P. Eggleton. 1995. On the elevated intestinal $\mathrm{pH}$ of higher termites (Isoptera: Termitidae). Insect Soc. 42: 5769.

6) Bignell, D.E., H. Oskarsson, J.M. Anderson and P. Ineson. 1983. Structure, microbial associations and function of the socalled "mixed segment" of the gut in two soil-feeding termites, Procubitermes aburiensis and Cubitermes severus (Termitidae, Termitinae). J. Zool. Lond. 201: 445-480.

7) Brune, A. 1998. Termite guts: the world's smallest bioreactors. Trends Biotechnol. 16: 16-21.

8) Brune, A., D. Emerson and J.A. Breznak. 1995. The termite gut microflora as an oxygen sink: microelectrode determination of oxygen and $\mathrm{pH}$ gradients in guts of lower and higher termites. Appl. Environ. Microbiol. 61: 2681-2687.

9) Brune, A. and M. Kühl. 1996. pH profiles of the extremely alkaline hindguts of soil-feeding termites (Isoptera: Termitidae) determined with microelectrodes. J. Insect Physiol. 42: 11211127.

10) Dadd, R.H. 1975. Alkalinity within the midgut of mosquito larvae with alkaline-active digestive enzymes. J. Insect. Physiol. 21: $1847-1853$.

11) Dow, J.A.T. 1984. Extremely high $\mathrm{pH}$ in biological systems: a model for carbonate transport. Am. J. Physiol. 246: R633-635.

12) Felsenstein, J. 1989. PHYLIP-phylogeny inference package (version 3.2). Cladistics 5: 164-166.

13) Felsenstein, J. 1985. Confidence limits on phylogenies: an approach using the bootstrap. Evolution 39: 783-791.

14) Felton, G.W. and S.S. Duffey. 1991. Reassessment of the role of gut alkalinity and detergency in insect herbivory. J. Chem. Ecol. 17: 1821-1836.

15) Gordon, R.E., W.C. Haynes and C.H.-N. Pang. 1973. The genus Bacillus. Agriculture Handbook no. 427. United States Department of Agriculture, Washington, D.C.

16) Heyndrickx, M., K. Vandemeulebroecke, P. Scheldeman, K. Kersters, P. De Vos, N.A. Logan, A.M. Aziz, N. Ali and R.C.W. Berkeley. 1996. A polyphasic reassessment of the genus Paenibacillus, reclassification of Bacillus lautus (Nakamura 1984) as Paenibacillus lautus comb. nov. and Bacillus peoriae (Montefusco et al. 1993) as Paenibacillus peoriae comb. nov., and emended description of $P$. lautus and $P$. peoriae. Int. J. Syst. Bacteriol. 46: 988-1003.

17) Hongoh, Y., M. Ohkuma and T. Kudo. 2003. Molecular analysis of bacterial microbiota in the gut of the termite Reticulitermes speratus (Isoptera; Rhinotermitidae). FEMS Microbiol. Ecol. 44: 231-242.

18) Hongoh, Y., H. Yuzawa, M. Ohkuma and T. Kudo. 2003. Evaluation of primers and PCR conditions for the analysis of 16S rRNA genes from a natural environment. FEMS Microbiol. Lett. 221: 299-304.

19) Horikoshi, K. 1999. Alkaliphiles: some applications of their products for biotechnology. Microbiol. Mol. Biol. Rev. 63: 735-750.

20) Ji, R. and A. Brune. 2001. Transformation and mineralization of ${ }^{14} \mathrm{C}$-labeled cellulose, peptidoglycan, and protein by the soilfeeding termite Cubitermes orthognathus. Biol. Fertil. Soils 33: 166-174.

21) Ji, R., A. Kappler and A. Brune. 2000. Transformation and mineralization of synthetic ${ }^{14} \mathrm{C}$-labeled humic model compounds by soil-feeding termites. Soil Biol. Biochem. 32: 1281-1291.

22) Kappler, A. and A. Brune. 1999. Influence of gut alkalinity and 
oxygen status on mobilization and size-class distribution of humic acids in the hindgut of soil-feeding termites. Appl. Soil. Ecol. 13: 219-229.

23) Kitada, M. and K. Horikoshi. 1987. Bioenergetic properties of alkalophilic Bacillus sp. strain C-59 on an alkaline medium containing $\mathrm{K}_{2} \mathrm{CO}_{3}$. J. Bacteriol. 169: 5761-5765.

24) Kitada, M., S. Morotomi, K. Horikoshi and T. Kudo. 1997. $\mathrm{K}^{+} / \mathrm{H}^{+}$antiporter in alkaliphilic Bacillus sp. no. 66 (JCM 9763). Extremophiles 1: 135-141.

25) Komagata, K. and K. Suzuki. 1987. Lipids and cell-wall analysis in bacterial systematics. Methods Microbiol. 19: 161-203.

26) König, H., J. Fröhlich, M. Berchtold and M. Wenzel. 2002. Diversity and microhabitats of the hindgut flora of termites. Recent Res. Devel. Microbiol. 6: 125-156.

27) Nakamura, L.K. 1984. Bacillus amylolyticus sp. nov., nom. rev., Bacillus lautus sp. nov., nom. rev., Bacillus pabuli sp. nov., nom. rev., and Bacillus validus sp. nov., nom. rev. Int. J. Syst. Bacteriol. 34: 224-226.

28) Noirot, C. 1992. From wood- to humus-feeding: an important trend in termite evolution. p. 107-119. In J. Billen (ed.) Biology and evolution of social insects. Leuven University Press, Belgium.

29) Ohkuma, M. 2003. Termite symbiotic systems: efficient biorecycling of lignocellulose. App. Microbiol. Biotechnol. 61: 1-9.

30) Ohkuma, M. 2002. Symbiosis in the termite gut: culture-independent molecular approaches. p. 717-730. In J. Seckbach (ed.) Symbiosis: mechanisms and model systems. Kluwer Academic Publishers, Dordrecht, Netherlands.

31) Ohkuma, M. and T. Kudo. 1998. Phylogenetic analysis of the symbiotic intestinal microflora of the termite Cryptotermes domesticus. FEMS Microbiol. Lett. 164: 389-395.

32) Ohkuma, M. and T. Kudo. 1996. Phylogenetic diversity of the intestinal bacterial community in the termite Reticulitermes speratus. Appl. Environ. Microbiol. 62: 461-468.

33) Priest, F.G., M. Goodfellow and C. Todd. 1988. A numerical classification of the genus Bacillus. J. Gen. Microbiol. 134: 1847-1882.
34) Saitou, N. and M. Nei. 1987. The neighbor-joining method: a new method for reconstructing phylogenetic trees. Mol. Biol. Evol. 4: 406-425.

35) Schäfer, A., R. Konrad, T. Kuhnigk, P. Kämpfer, H. Hertel and H. König. 1996. Hemicellulose-degrading bacteria and yeasts from the termite gut. J. Appl. Bacteriol. 80: 471-478.

36) Shida, O., H. Takagi, K. Kadowaki, L.K. Nakamura and K. Komagata. 1997. Transfer of Bacillus alginolyticus, Bacillus chondroitinus, Bacillus curdlanolyticus, Bacillus glucanolyticus, Bacillus kobensis, and Bacillus thiaminolyticus to the genus Paenibacillus and emended description of the genus Paenibacillus. Int. J. Syst. Bacteriol. 47: 289-298.

37) Sleaford, F., D.E. Bignell and P. Eggleton. 1996. A pilot analysis of gut contents in termites from the Mbalmayo Forest reserve, Cameroon. Ecol. Entomol. 21: 279-288.

38) Tamaoka, J. and K. Komagata. 1984. Determination of DNA base composition by reverse-phase high-performance liquid chromatography. FEMS Microbiol. Lett. 25: 125-128.

39) Thongaram, T., S. Kosono, M. Ohkuma, Y. Hongoh, M. Kitada, T. Yoshinaka, S. Trakulnaleamsai, N. Noparatnaraporn and T. Kudo. 2003. Gut of higher termites as a niche for alkaliphiles as shown by culture-based and culture-independent studies. Microb. Environ. 18: 152-159.

40) Tompson, J.D., D.G. Higgins and T.J. Gibson. 1994. CLUSTAL $\mathrm{W}$ : improving the sensitivity of progressive multiple sequence alignment through sequence weighting, positions-specific gap penalties and weight matrix choice. Nucleic Acids Res. 22: 46734680.

41) Yoon, J.-H., D.K. Yim, J.-S. Lee, K.-S. Shin, H.H. Sato, S.T. Lee, Y.K. Park and Y.-H. Park. 1998. Paenibacillus campinasensis sp. nov., a cyclodextrin-producing bacterium isolated in Brazil. Int. J. Syst. Bacteriol. 48: 833-837.

42) Wenzel, M., I. Schönig, M. Berchtold, P. Kämpfer and H. König. 2002. Aerobic and facultatively anaerobic cellulolytic bacteria from the gut of the termite Zootermopsis angusticollis. J. Appl. Microbiol. 92: 32-40. 